\title{
Assessing housing: developing a method for neighbourhood ecological footprint analysis
}

\author{
R. E. Smith ${ }^{1} \&$ M. Senbel ${ }^{2}$ \\ ${ }^{1}$ University of Utah, College of Architecture and Planning, USA \\ ${ }^{2}$ University of British Columbia, \\ School of Community and Regional Planning, Canada
}

\begin{abstract}
Most large-scale ecological footprint (EF) studies provide convincing evidence to state and regional elected officials that might result in regional or state-level environmental policy. This study seeks to address a much smaller scale of environmental policy and addresses a gap in the literature. It is targeted at local decision makers of the built environment including the professional design community of planners, urban designers, and architects and seeks to influence neighbourhood design and form. During our analysis, however, the findings revealed shortcomings in the data gathering method that produced inaccuracies in EF results at this smaller scale. The project therefore shifted its focus towards developing a data gathering method for future neighbourhood scale EF evaluations.

Keywords: ecological footprint, life cycle assessment, materials flow analysis.
\end{abstract}

\section{Introduction}

Since Rees and Wackernagel's seminal book [1] Ecological Footprint (EF) analysis has gained in popularity as an environmental impact assessment tool because of the accessibility of its technique and simplicity of interpretation. EF is an accounting method that illustrates the environmental impacts of human consumption by translating consumption into the land and marine areas required to provide resources for the consumption and absorptive capacity for the wastes associated with consumption. EF studies are diverse in scale including evaluations of nations, regions, states, cities, and even individual lifestyles [2]. The EF is calculated in global hectares (gha), which is an area measurement 
correcting for a wide variety of ecological productivity between different parts of the earth. Ideally, EF accounts for all aspects of consumption of resources and assimilation of wastes. The EF is, therefore, a feedback tool to tell us how sustainable we are living within our resources on the planet.

Most environmental impact studies utilizing the EF method focus on large areas such as regions or cities, relying upon macro purposed algorithms to calculate per capita consumption versus the necessary land and marine areas required to support that consumption [3]. The quality of the macro level information, for example census data, for large-scale studies is appropriate, however for this study, an EF of a neighbourhood, the base line algorithms and census data was not available at a fine enough resolution [4]. The study set out to evaluate and compare the EF of three neighbourhoods each comprising a $1 / 2$ mile radius within their respective city existing in the Salt Lake Valley. The specific areas evaluated were identified as representative of typical for the cities in which they were enveloped.

As opposed to large-scale EF studies, whose purpose is to provide convincing evidence to state and regional elected officials that might result in smart-growth initiatives or metropolitan environmental policies, this study is targeted at local decision makers of the built environment including the professional design community of planners, urban designers, and architects to influence neighbourhood design and form. During the research, however, the findings pointed toward gaps in the available data that undermined the replicability of the neighbourhood scale results. The research diverted therefore away from finding results of an EF to provide to the design community to that of the development of a data gathering method for future neighbourhood scale EF evaluations.

Consumption Land Use Matrix

\begin{tabular}{|l|l|l|l|l|l|l|l|}
\hline & $\begin{array}{c}\text { Built-up } \\
\text { Land }\end{array}$ & CO2 Area & Cropland & $\begin{array}{c}\text { Grazing } \\
\text { Land }\end{array}$ & Forest & $\begin{array}{c}\text { Fishing } \\
\text { Ground }\end{array}$ & Total \\
\hline Food & & & & & & & \\
\hline Shelter & & & & & & & \\
\hline Mobility & & & & & & & \\
\hline Goods & & & & & & & \\
\hline Services & & & & & & & \\
\hline Total & & & & & & \\
\hline
\end{tabular}

Figure 1: EF analysis components from the 2006 Ecological Footprint Standards developed by the Global Footprint Network [5]. The matrix illustrates the essence of EF studies, which is human consumption versus the bio capacity necessary to supply that consumption.

\section{Method}

The study utilized the 2006 Ecological Footprint Standards developed by the Global Footprint Network, which considers food, shelter, mobility, goods, and services in assessing the consumption of built up land, $\mathrm{CO} 2$ areas, cropland, grazing land, forest, and fishing ground use, fig. 1. Due to the initial goals of the 
study, to influence the design professions regarding development patterns, the study limited its scope to the footprint of the individual resident in a particular neighbourhood. The study was broken into two data gathering modes and then combined at the end to form a complete EF analysis utilizing Stella modelling software. Due to a lack of data and a desire to focus the study on planning and architectural issues, the EF study was isolated to mobility and shelter specifically. Mobility or transportation consists of calculating bicycle, private automobile, and public transportation including train and bus, and air travel footprint areas. The assessment of mobility relied on Holtsclaw's equations of propensity to use different modes of transport depending on the availability and proximity of transit services [6]. As the study was taking a more detailed scale assessment of EF at the neighbourhood scale, quantifying the EF of housing became the critical and unique element of the study. The need for an increased accuracy and sophistication in the data gathering method for consumption associated with the construction, occupancy and demolition of housing became increasingly apparent, fig. 2 .

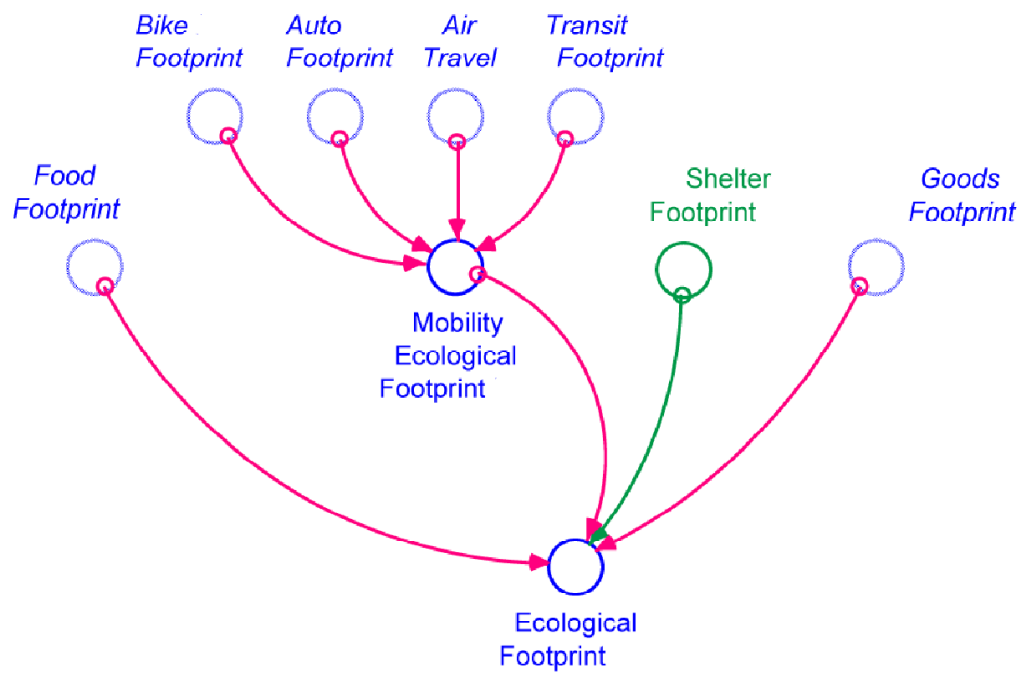

Figure 2: EF software Stella Graphic that shows the context of a full EF study including Mobility, Shelter, Food, and Goods. The authors' study set out to evaluate physical planning and architecture topics, Mobility and Shelter specifically.

\section{Assessing "shelter"}

A number of studies have been performed to quantify the EF of shelter. The Stockholm Environment Institute's study titled, Sustainability Rating for Homes - The Ecological Footprint Component is a similar scale to the authors' study, however focused on results, not method [7]. Upon inspection of the report, 
questions regarding the quality of the data in the rating system emerged in the authors' mind. Other studies have evaluated the life-cycle energy of residences in order to show how passive, or more efficient buildings perform well over a neighbourhood, but have not put the study in terms of EF. This is important to the authors' investigation as to contribute to a larger EF study for the neighbourhood that includes the transportation criteria in addition to a regional level EF that might be simultaneously conducted. The data would then feed into a larger model, showing the effects of an architectural decision for a development upon the regional EF model.

Blanchard and Reppe's report titled, Life Cycle Analysis of a Residential Home in Michigan in 1998 illustrates the need for a full life cycle energy assessment of shelter in order to quantify its environmental impacts [8]. Utilizing this approach for the purpose of EF was determined to be the most detailed and accurate method. The energy in mega joules was converted through a number of calculations to land area in global hectares. Life Cycle Assessment (LCA) procedures are part of the International Organization for Standardization 14000 environmental standards [9]. An advantage of using the LCA procedures to feed an EF study is that LCA can potentially cover a wide variety of impacts not accounted for in EF larger scale studies such as more detailed data concerning the life cycle energy of specific materials and operation of the houses in the neighbourhoods in question. Other benefits of utilizing LCA including human toxicity and acidification accounting were not used in this study, but should be noted.

ISO sections 14040 and 14044 identify 4 phases in order to perform an LCA: 1- goal and scope; 2 - life cycle inventory; 3 - life cycle impact assessment; and 4interpretation. The goal and scope of assessing shelter is quantifying the total energy consumption over the life cycle of a house. The inventory in order to accomplish this goal includes both construction energy, including the embodied energy of materials, the energy of construction, maintenance energy and demolition/recycle energy; and operational energy including HVAC, power and gas to operate the facility.

Operational energy data was obtained from the Utah energy statistics as a State, and by industry including residential per capita [10]. The data, however, was not aggregated by city or neighbourhood, see fig. 3. Construction energy information was developed through a complication of publications and data services that provide information on embodied energy of materials [11]. A key factor in determining embodied energy is the transportation energy required to transport materials to the site of installation. Due to a lack of existing data for transportation energy for the Salt Lake Valley, the authors chose to exclude this factor for the equation for construction energy. In addition, no data was readily available to consider the energy of on site construction and installation, maintenance and demolition.

In order to develop accurate data for the construction energy aggregated by house, profiles were built that identified the different building types within each neighbourhood. For example, in one neighbourhood, three types were established indicating the site and house size, quantifying the amount of material 
and land consumption per residence. Once profile types for houses were developed for each neighbourhood, material profiles were developed for each construction system in the houses in question based on the embodied energy of the materials from cradle to gate. The systems datasets created include foundation, exterior wall, interior wall, roof, floor structure, finish floor, ceiling, driveway, millwork, plumbing, electrical and mechanical respectively, fig. 4. The quantity profiles were then multiplied by the system profiles to determine the total life cycle energy for each house in each neighbourhood. A conversion from energy to land area was then performed. The data was summed (construction $\mathrm{EF}+$ operation $\mathrm{EF}+$ land EF) and then factored by the number of persons per household to aggregate the data per capita to determine the EF per neighbourhood, fig. 5.

\begin{tabular}{|c|c|c|}
\hline Energy Use & & $0.70 \mathrm{gha}$ \\
\hline Construction & & $0 \mathrm{gha}$ \\
\hline Electricity & & \\
\hline Fossil Fuels & & \\
\hline Building Opcration & & $0.70 \mathrm{gha}$ \\
\hline Electricity & 2,949ilowatt-hours per capita per year & \\
\hline & $0.43 \mathrm{CO} 2$ Emissions (kg per kWH) & \\
\hline & 111Global Hetares required per GWh & $0.33 \mathrm{gha}$ \\
\hline Natural Gas & 7,620Kilowatt-hours per capita per year & \\
\hline & $0.19 \mathrm{CO} 2$ Emissions ( $\mathrm{kg}$ per $\mathrm{kWH}$ ) & \\
\hline & 49 Global Hetares required per GWh & 0.37gha \\
\hline
\end{tabular}

Figure 3: Operational energy accounted for in the EF study were electricity and natural gas. These values were based on the consumption average for the size of house. Water is noticeably absent as it is in most EF studies. Methods for quantifying EF as a function of water consumption are currently being evaluated.

The life cycle energy study of individual houses was taken as the shelter function and wrapped into the larger EF analysis including mobility.

\section{Findings}

In order to be accurate in the LCA that feeds the EF, a more detailed and discriminating method of gathering data is necessary. Various tools exists to collect these pieces of data, however many are expensive and the format of the software are not interoperable. In order to provide a more accurate assessment of individual building EF from LCA, three pieces are necessary: construction energy, including 1 - A material take off calculator, 2- A material embodied energy and carbon inventory calculator; and operational energy, including 3 - an energy consumption calculator [12]. 


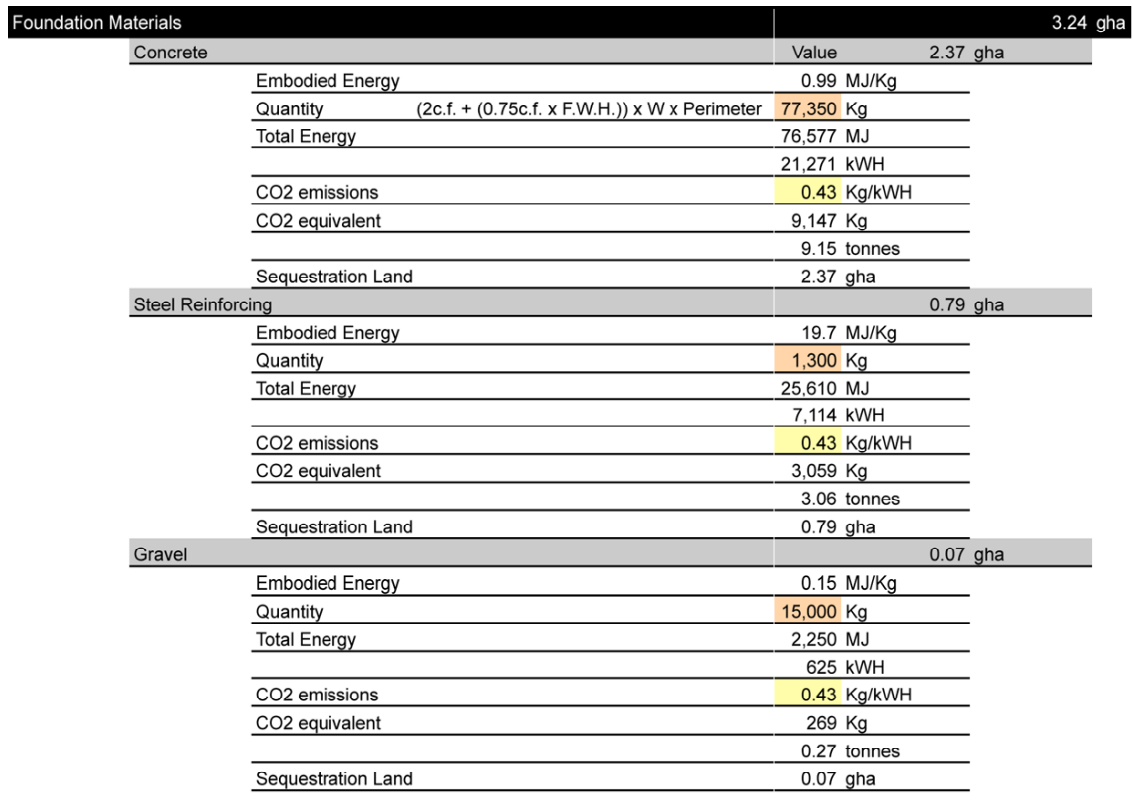

Figure 4: Foundation system profile is illustrated.

For our study material take offs were taken as averages based on the square footage of the home. Future studies should develop material take off models in order to obtain accurate readings on quantities for typical homes. Materials inventory should take into consideration material mass and life cycle energy. Material quantity estimating software is available. For example, CAD Estimator and Esti-Mate are both contractor tools for bidding and negotiating contracts for construction specific to materials quantity calculation for estimation consulting firms and construction companies [13]. Ideally, material take-offs should utilize a Building Information Model (BIM).

Building Information Modelling (BIM) is an emerging information technology in the architecture/ engineering/ construction (AEC) industry. The basic concept of BIM is to describe a building project in a set of digital databases, referred to as the BIM model. BIM data is structured around objects that correspond to elements of a project such as walls, columns and slabs. The data may include the object's geometry, which permits the generation of visual representations of the project in two or three dimensions, and virtually any information relevant to the project such as materials, physical properties, manufacturer information, etc. Among the promises of BIM are virtual constructions that allow for accurate costing and scheduling; representations that are consistent and well coordinated; parametric capabilities with intelligent objects that derive information from data so that performance modelling such as structural and energy modelling are simulated; and digital fabrication capabilities for a more direct connection between design and fabrication [14]. For EF, BIM 


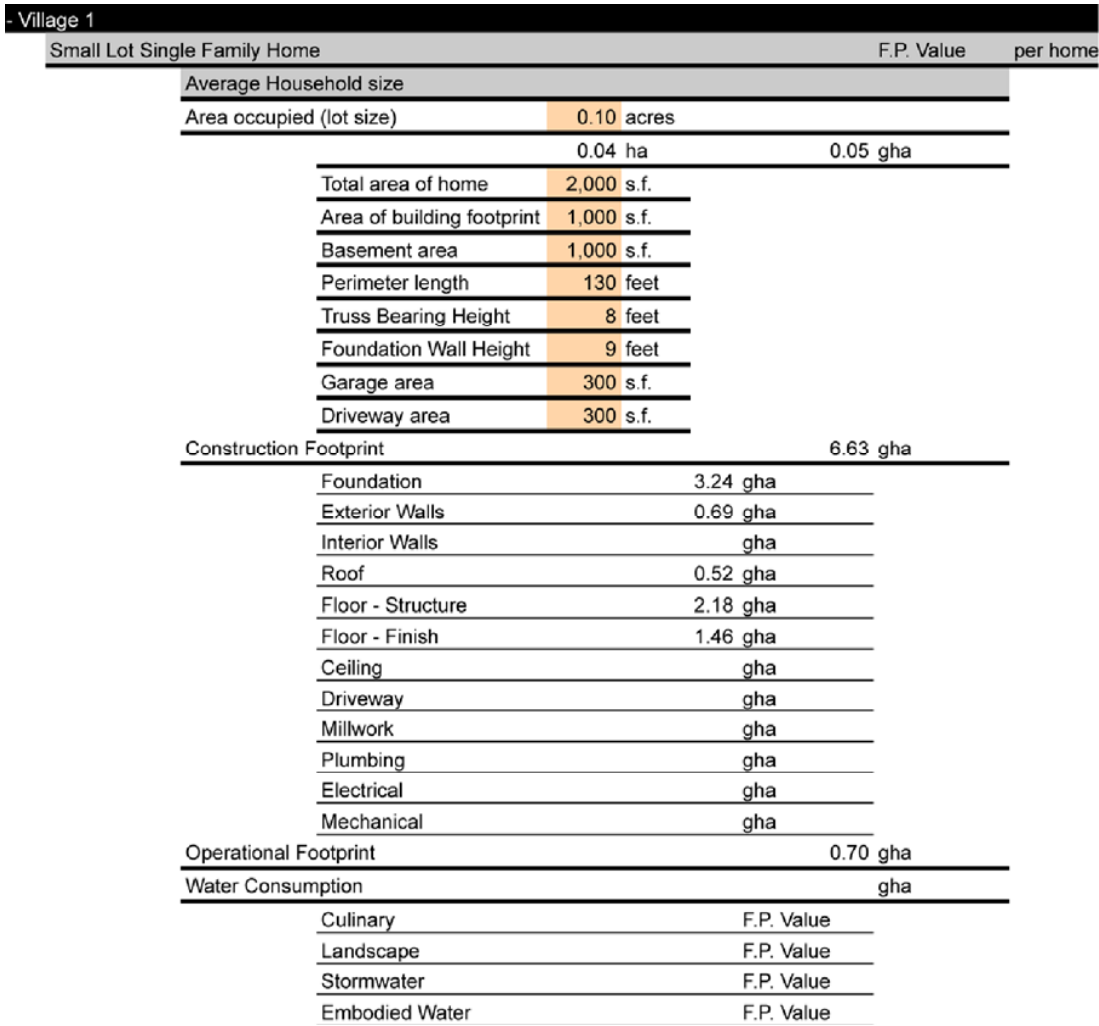

Figure 5: A neighbourhood assessment per house. This value is divided per capita to produce the EF for the entire neighbourhood.

generation would be the most accurate method for material quantity information where the density of each material is included in the database. Costing information included in the attributes of the model would allow for an effective cost-benefit analysis between system design decisions, economics and EF.

In this study the data for material inventory of embodied energy was taken from various sources, some of which conflicted in their values. Existing data sets available for download that offer information on life cycle energy include the following: DEAM Database, which is a fee per material dataset download. BEES 3.0, which offers datasets for over 200 construction materials produced by the National Institute of Building Standards [15]. US LCI Database Project is another set but is limited in its offering of energy information on materials [16]. These sources provide embodied energy and carbon in addition to mass and densities of materials. This data in association with material take-off calculator provides the information for life cycle material energy. Future studies should try and locate a materials inventory dataset that allows for flexibility in the location of the study (i.e. Salt Lake Valley) to ensure that the consumption of the availability of energy and the transportation from gate to site is included. 
Utilizing BIM, material inventory data can be included as attributes of material systems for a more comprehensive output of life cycle energy.

Information concerning the energy consumed by fuelling construction vehicles and machinery on site was not found and therefore was not evaluated due to time constraints and uncertainty as to how to obtain this data. It should be noted however that this type of consumption represents the most insignificant amount of energy consumption of all the phases of the life cycle of a house. Future studies will focus on developing simplistic algorithms to account for this energy per system (i.e. system install energy + maintenance energy + demolition/recycle energy). It is possible that a BIM can be used for these calculations as well.

Although data exists for operational energy consumption at the state level, the authors have discovered that two of the cities in the Salt Lake Valley under investigation have utility rate information available to the public. For future evaluation, these averages will be taken for the household operational calculation. For the third neighbourhood, the municipality and power company are unwilling to provide the data; therefore a speculation must be determined based on the data from the other neighbourhoods considering the size of the house. In addition to gathering data from cities and power/gas companies, simulation of specific model homes will need to be run coupled with monitoring of existing homes. Both should be done in order to ensure the simulation is accurate. Simulation software commercially available include Energy 10 Software which allows for modelling different system options including day lighting, passive solar heating and cooling, ventilation, envelope, windows, artificial illumination, and mechanical systems [17]. Other software available today include aforementioned BIM, but purpose built for energy calculations. The most notable, Eco-tect, is a tool that can upload a BIM base model that has been properly attributed and tests it for performance with regard to the criteria of energy over the life of the building [18]. Utilizing the BIM for both construction energy and operational energy would provide a more accurate and useful mechanism for calculating LCA and finally EF.

\section{Conclusion}

It is clear that the method for quantifying the EF of shelter is difficult at best. This is due to the difficulty in obtaining project specific energy data at the scale of an individual housing unit. Typical EF calculations use average data sets for categories of building types. In order to quantify environmental impact at the neighbourhood or even household scale, much more detailed data is necessary. The operational energy accounts for $90 \%$ of the total energy consumption by a house during its life cycle. Therefore, trying to develop a system for quantification of construction energy is not as critical as establishing a method for quantifying the operational energy of a housing unit over its entire lifecycle. However, a BIM purpose built modeller would allow for all of the construction energy and operational energy to be comprehensively calculated. Together these tools conceptually would make for a powerful LCA calculator and conversion to 
EF on shelter. This information would provide the design professions including planners, urban designers, architects and code officials the ability to assess decisions of neighbourhood design and architectural form and their impacts over the life of the building. By assessing LCA in terms of EF, the information would allow for the data concerning shelter to be more accurate, detailed, and determinant in EF evaluations for cities, regions, states, and countries.

\section{References}

[1] Rhees, William and Wackernagel, Mathias. Our Ecological Footprint: Reducing Human Impact on the Earth. New Society Publishers. 1995

[2] Barrett, J., Vallack, H. Jones, A., Haq, G. A Material Flow Analysis and Ecological Footprint of York. Stockholm Environment Institute. Norwich Union.

[3] Aall, Carlo and Norland, Ingrid Thorsen. Report no. 11/02 The Ecological Footprint of the City of Oslo- Results and Proposals for the Use of the Ecological Footprint in Local Environmental Policy. Western Norway Research Institute. Prosus 2002.

[4] Hoyer, Karl G. and Holden, Erling. Household Consumption and Ecological Footprints in Norway - Does Urban Form Matter? Journal of Consumer Policy 2003. 327-349. Kluwer Academic Publishers Netherlands 2003.

[5] Ecological Footprint Standards 2006. Global Footprint Network. June 16, 2006.

[6] Holtzclaw, J.; Designing Cities to Reduce Driving and Pollution: New Studies in Chicago, LA and San Francisco; Air \& Waste Management Association: Pittsburgh, June 8-13, 1997. http://www.sierraclub.org/sprawl

[7] Wiedmann, T., Barrett, J., and Cherrett, N. Sustainability Rating for Homes The Ecological Footprint Component. Stockholm Environment Institute. 2003.

[8] Blanchard, S. and Reppe, P. Life Cycle Analysis of a Residential Home in Michigan. Center for Sustainable Systems University of Michigan. Report No. 1998-5. September 1998.

[9] ISO 14000 Environmental Impact Industry Standards. International Organizing Standards.

[10] Energy Information Administration. Utah State Energy Data 2003: Consumption. Table S4. Residential Sector Energy Consumption Estimates, 2003.

[11] Hammond, Geoff and Jones, Craig. Inventory of Carbon and Energy (ICE) Version 1.5 Beta. University of Bath 2006.

[12] Shawkat, Hijram Ali. Sustainable Housing: Reducing the Ecological Footprint. Masters Thesis McGill University 1990's.

[13] http://www.ezhomebuild.com/cadestimating.asp

[14] Scheer, David \& Smith, Ryan. Download My Building: how building information modelling will transform our cities. Society and Cities in the Age of Instant Access. 57-70 Harvey Miller (Ed.) Springer, 2007. 
104 Eco-Architecture II

[15] http://www.bfrl.nist.gov/

[16] http://www.nrel.gov/lci/

[17] http://www.nrel.gov/buildings/energy10.html

[18] http://ecotect.com/home 